\title{
Aggregation and Fibrillation Study of $\alpha$-synuclein Under Applied Voltage
}

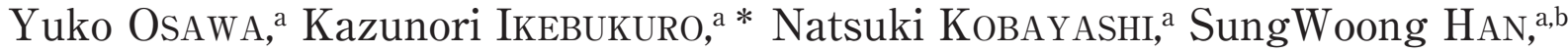 \\ Chikashi NAKAmura, a,b and Koji SoDE ${ }^{\mathrm{a}}$
}

\author{
aDepartment of Biotechnology and Life Science, Tokyo University of Agriculture and Technology (2-24-16 Naka- \\ cho, Koganei, Tokyo 184-8588, Japan) \\ ${ }^{b}$ Research Institute for Cell Engineering, National Institute of Advanced Industrial Science and Technology (2-41-6 \\ Aomi, Koto-ku, Tokyo 135-0064, Japan)
}

Received March 3, 2008 ; Accepted July 9, 2008

\begin{abstract}
The application of voltage has been used to control the movement of charged molecule such as DNA, some proteins and phospholipid in recent year. In this study, we first applied voltage to amyloidogenic protein, $\alpha$-synuclein, which is related to Parkinson's disease. To offer the new approach using electric field and new insight into aggregation and fibrillation mechanism of $\alpha$-synuclein, we tried to control the aggregation of $\alpha$-synuclein, which has a negative charge, by applying voltage to it. The aggregation of $\alpha$-synuclein without conformational change occurred rapidly when a voltage of $1 \mathrm{~V}$ was applied. The protein did not form amyloid-like fibrils, but it did form small aggregates. These results demonstrate that this technique might be useful not only to efficiently control aggregation of $\alpha$-syn but also to understand the mechanism of aggregation and fibrillation of $\alpha$-syn.
\end{abstract}

Key Words : Aggregation, Application of Voltage, $\alpha$-Synuclein, Natively Unfolded Protein

\section{Introduction}

The application of voltage has been used previously to control the movement of charged molecules such as DNA, some proteins and phospholipid; more precisely, it has been used to immobilize such molecules onto electrodes or control their mobility and orientations in electric field..$^{1-5)}$ The application of voltage can affect only the frequency of collision of the charged molecules, not the protein-protein interaction, in contrast to chemical conditions such as low pH, and so on. Therefore, in principle, charged proteins can be made to collide and aggregate efficiently if the voltage is applied. However, no reports have so far described the aggregation of charged proteins under applied voltage.

Protein aggregation is associated with some diseases such as amyloidosis (Alzheimer's disease, Parkinson's disease, Huntington's disease and others) ${ }^{6-9)}$ Thus, the control of protein aggregation by means of applied voltage might be useful in elucidating the mechanisms involved and developing therapeutical methods.

One of the amyloidogenic proteins is $\alpha$-synuclein $(\alpha$ syn). This protein is a small presynaptic protein $(14 \mathrm{kDa})$ and is found abundantly in various regions of the brain. ${ }^{10,11)}$ The $\alpha$-syn fibrillated via aggregation forms deposits in the brain and induces Parkinson's disease (PD). ${ }^{7,8,10-13)}$ The primary structure of $\alpha$-syn comprises three characteristic regions; an amphiphilic region at the $\mathrm{N}$-terminus, a hydrophobic region in the middle called NAC (Non-A $\beta$ Component of Alzheimer's disease amyloid) which is assumed to be an nucleus of aggregation of $\alpha$-syn, and an acidic region at the C-terminus. ${ }^{14,15)}$ Structurally, it belongs to the group of natively unfolded proteins, characterized by a lack of ordered structure under physiological conditions. ${ }^{16,17)}$ As $\alpha$-syn has a highly negative charge at the C-terminus in neutral $\mathrm{pH}$ conditions, the resulting repulsive interactions are a major factor leading to the natively unfolded structure of this protein. ${ }^{18)}$ The $\alpha$-syn also readily forms fibrils in vitro, with morphology and staining characteristics similar to those of fibrils extracted from the brains of PD's patients. ${ }^{17,19)}$ The kinetic mechanism of $\alpha$-syn fibrillation is considered nucleation-dependent; that is, the critical early stage involves the nucleus of $\alpha$-syn via aggregation after their folding process to partially folded intermediate. Under various conditions, for example, low $\mathrm{pH}$, high temperature and so on, the aggregation and fibrillation of $\alpha$-syn have already been examined and controlled. ${ }^{17,20)}$ However, it is difficult to investigate interaction between $\alpha$-syn itself under these conditions such as low $\mathrm{pH}$ since these conditions change the chemical environment of $\alpha$ syn.

To offer the new approach and new insight into aggregation and fibrillation mechanism of $\alpha$-syn, we focused on the application of voltage. We presumed that $\alpha$-syn would gather near the electrode and concentrate easily under applied voltage because the protein has highly negative charges, and that the collision of $\alpha$-syn might be promoted. However, the application of voltage for the purpose of accelerating the aggregation and fibrillation of $\alpha$-syn has never been tried. Thus, we tried to apply voltage to $\alpha$-syn in order to accelerate its aggregation. We evaluated the effect of the applied voltage on the aggregation and fibrillation of $\alpha$-syn. 


\section{Experimental}

\section{1 Expression and purification of human $\alpha$-syn}

Human recombinant $\alpha$-syn was expressed in Escherichia coli BL21 (DE3) transfected with pET28a/human $\alpha$-syn wild type plasmid. The expression and purification of human $\alpha$-syn was carried out as described previously. ${ }^{21)} \alpha$-Syn expression was induced by the addition of $0.3 \mathrm{mM}$ isopropyl-1-thiob- D-galactopyranoside (IPTG). The cell pellet was collected by centrifugation at 5,000 $\mathrm{G}$ for $10 \mathrm{~min}$ and resuspended in cell lysis buffer $(20 \mathrm{mM}$ Tris-HCl, pH 8.0, 1 mM EDTA, $50 \mathrm{mM}$ $\mathrm{NaCl})$. It was homogenized by French press and centrifuged at $18,500 \mathrm{G}$ for $10 \mathrm{~min}$ at $4{ }^{\circ} \mathrm{C}$. The supernatant was collected, incubated in a boiling water bath for 20 min, and centrifuged at $18,500 \mathrm{G}$ for $10 \mathrm{~min}$ at $4{ }^{\circ} \mathrm{C}$. The supernatant was dialyzed overnight in $20 \mathrm{mM}$ Tris- $\mathrm{HCl}$, $\mathrm{pH}$ 8.0. After centrifugation $\left(12,000 \mathrm{G}, 20 \mathrm{~min}, 4^{\circ} \mathrm{C}\right)$, It was applied to a Resource Q $1 \mathrm{ml}$ column for ion exchange chromatography (GE Healthcare Bio-Science Corp., Sweden) and the fractions containing $\alpha$-syn were eluted with a $\mathrm{NaCl}$ gradient (final concentration, $0.5 \mathrm{M}$ ) in $20 \mathrm{mM}$ Tris- $\mathrm{HCl}, \mathrm{pH}$ 8.0. The protein fractions were collected and dialyzed against $10 \mathrm{mM}$ Tris- $\mathrm{HCl}, \mathrm{pH} 7.4$. The purity was confirmed by SDS-PAGE. The protein concentration was determined using a DC protein assay kit (Bio-Rad Laboratories Inc., CA, USA).

\section{2 Materials}

Thioflavin T (TfT) was purchased from Sigma (St. Louis, MO, USA). Lysozyme was purchased from Wako Chemicals (Osaka, Japan). All other chemical reagents used were of analytical grades.

\section{3 Application of voltage}

The insoluble oligomer of $\alpha$-syn was removed by ultracentrifugation $\left(150,000 \mathrm{G}, 1 \mathrm{~h}, 4{ }^{\circ} \mathrm{C}\right)$. A gold wire electrode as the working electrode and a platinum wire electrode as the counter electrode were immersed into the reaction solution containing $70 \mu \mathrm{M} \alpha$-syn or control protein (lysozyme) in $10 \mathrm{mM}$ Tris- $\mathrm{HCl}$ buffer, $\mathrm{pH}$ 7.4. The volume of this reaction solution was $1 \mathrm{ml}$ and the distance between electrodes was about $5 \mathrm{~mm}$ in $1.5 \mathrm{ml}$ of eppendorf tube as electrolysis cell. Electric pulses, $3 \mathrm{~s}$ on and 3 $\mathrm{s}$ off at $+1 \mathrm{~V}$, were applied to the solution at $37^{\circ} \mathrm{C}$ using a HZ3000 electrochemical analyzer (Hokuto-Denko, Tokyo, Japan). Cyclic voltammogram (CV) measurements were carried out using a gold electrode as the working electrode, a platinum electrode as the counter electrode and an $\mathrm{Ag} / \mathrm{AgCl}$ electrode as the reference electrode in the reaction solution to confirm the measurement condition. The potential was cycled between $\pm 1.5 \mathrm{~V}$ with a sweep rate of $10 \mathrm{mV} \mathrm{s}^{-1}$ using the same electrochemical analyzer.

\section{4 Light scattering assay}

The aggregation of $\alpha$-syn was monitored using light scattering at $330 \mathrm{~nm}$. A light scattering assay was carried out as described previously. ${ }^{21-23)}$ At each time during application of voltage, we took a sample from $\alpha$-syn solution and measured their light scattering at $330 \mathrm{~nm}$. These samples were diluted when necessary.

\section{5 Circular dichroism (CD) measurements}

The CD spectra of $\alpha$-syn was measured with a spec- trophotometer (J720, Jasco, Japan) as described previously. ${ }^{22,23)}$ After applied voltage for $18 \mathrm{~h}$, the large insoluble oligomer was removed by centrifugation and the supernatant of $\alpha$-syn solution, including soluble oligomer, was diluted to threefold (about $23 \mu \mathrm{M}$ ). The Spectra of the prepared samples were measured from 190 to $250 \mathrm{~nm}$ at $25{ }^{\circ} \mathrm{C}$ with a bandwidth of $1.0 \mathrm{~nm}$, a step resolution of 0.2

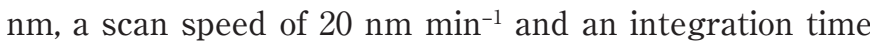
of 4 s. For all spectra, the average of three scans was obtained.

\section{6 Thioflavin $\mathrm{T}$ binding assay}

The fibrillation of $\alpha$-syn was monitored after the application of voltage using Thioflavin $\mathrm{T}$ (TfT) fluorescence at $482 \mathrm{~nm}$ on a fluorescence spectrometer (FP6500, Jasco, Japan) as described previously. ${ }^{21-23)}$ At each time during application of voltage, we took a sample from $\alpha$-syn solution. The intensity of TfT fluorescence at $482 \mathrm{~nm}$ was measured immediately after the addition of the protein solution to the TfT solution (final conc.; $25 \mu \mathrm{M}$ ) using a $0.3 \mathrm{~cm}$ path length quartz cell at an excitation of $450 \mathrm{~nm}$, a bandwidth of $5 \mathrm{~nm}$, an integration time of $1 \mathrm{~s}$ and a step resolution of $1 \mathrm{~nm}$. The spectra of the buffers were also measured and subtracted from that of the proteinTfT mixture.

\section{7 Atomic force microscopy}

Each $\alpha$-syn sample was prepared by depositing $5 \mu \mathrm{l}$ of the solution on freshly cleaved mica. After the absorption of the protein for approximately $5 \mathrm{~min}$, the surface of the mica was gently washed with deionized water to remove the redundant buffer and the protein that was not firmly attached to the mica. The mica was dried for approximately $5 \mathrm{~min}$ to remove the excess water. All images were obtained using a Molecular Force Probe (MFP) 3D (Asylum Research, Santa Barbara, California) by tapping mode imaging with a cantilever (Micro cantilever OMCL-AC160TS-C2, Olympus, Tokyo, Japan). The scanning parameters varied with the individual samples. Some typical parameters were as follows: driving amplitude, $415.35 \mathrm{mV}$; set point, $769.75 \mathrm{mV}$; resonant frequency, $294.927 \mathrm{kHz}$; scan rate, $0.60 \mathrm{~Hz}$.

\section{Results and Discussion}

\section{1 Effect of applying $1 \mathrm{~V}$ on the aggregation of $\alpha$ - syn}

In the experiment using the application of voltage, the non-production of chemically reactive species should be confirmed because the application of voltage can produce chemically reactive species that affect the properties of protein. The generations of such chemically reactive species under our experimental conditions was investigated by $\mathrm{CV}$ measurements. The results show that the electrolysis of water did not occur in the reaction solution at an electric potential between $-1 \mathrm{~V}$ and $+1 \mathrm{~V}$, and so chemically reactive species such as reactive oxygen species and radicals seemed not to be produced in the protein solution under these measurement conditions (data not shown). Similarly, the significant change of current and the generation of gases by electrolysis of water were neither observed when we apply the voltage to the protein solution using two electrodes. 


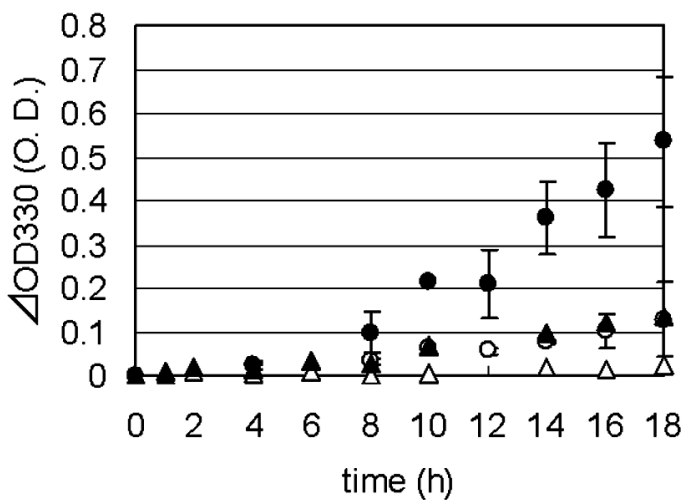

Fig. 1 Effect of applying a voltage of $1 \mathrm{~V}$ on the aggregation of $\alpha$-syn. The symbols represent the degree of light scattering of $\alpha$-syn under the application of no voltage $(\bigcirc)$ or voltage of $1 \mathrm{~V}(\mathbf{O})$ and the degree of light scattering of lysozyme under the application of no voltage $(\triangle)$ or voltage of $1 \mathrm{~V}(\boldsymbol{\Delta})$. The protein concentration of the solutions was $70 \mu \mathrm{M}$, at pH 7.4 and $37^{\circ} \mathrm{C}$.

A light scattering assay at $330 \mathrm{~nm}$ was carried out to monitor the aggregation of $\alpha$-syn under an applied voltage of $1 \mathrm{~V}$. It is known that light scattering from protein solutions reflects the formation of large particles. That is, the degree of light scattering is an association-dependent parameter. The increase in static light scattering will reflect the formation of all large particles, both fibrillar and amorphous (including large soluble oligomer). As shown in Fig. 1, the application of this voltage led to an obvious increase in the light scattering of the $\alpha$-syn solution with time. The light scattering of $\alpha$-syn after $18 \mathrm{~h}$ of applied voltage was four times as high as that of $\alpha$-syn under no voltage. We used lysozyme for the control experiment since it has a molecular weight similar to that of $\alpha$-syn, but its $\mathrm{pI}$ is 10.7 , higher than that of $\alpha$-syn, 4.7. The light scattering intensity of lysozyme did not change when voltage was applied. These results indicate that the aggregation of $\alpha$-syn was accelerated by the application of a voltage of $1 \mathrm{~V}$.

Since $\alpha$-syn does not form stable structure, its hydrophobic NAC regions collide and it would generate the nucleation core of aggregates. Unlike $\alpha$-syn, lysozyme natively folds into stable structure, and it did not denature and aggregate by application of a voltage of $1 \mathrm{~V}$. Lysozyme usually denatures and aggregates under certain condition such as high temperature or denaturant reagent. Therefore, this result indicates that the aggregation of $\alpha$-syn was accelerated by the collision of those NAC regions and generation of nucleation core of the aggregation.

In contrast to $\mathrm{CV}$ measurement, only two electrodes, including working electrode and counter electrode, were used during application of voltage to $\alpha$-syn. Thus, voltage between two electrode was just $1 \mathrm{~V}$ but the accurate potential was not clear. The significant change of potential was not observed in CV measurement. In addition, the potential of the working electrode in this experiment might be under $+1.2 \mathrm{~V}$ (the potential for electrolysis of water) since the electrolysis of water would not occur in

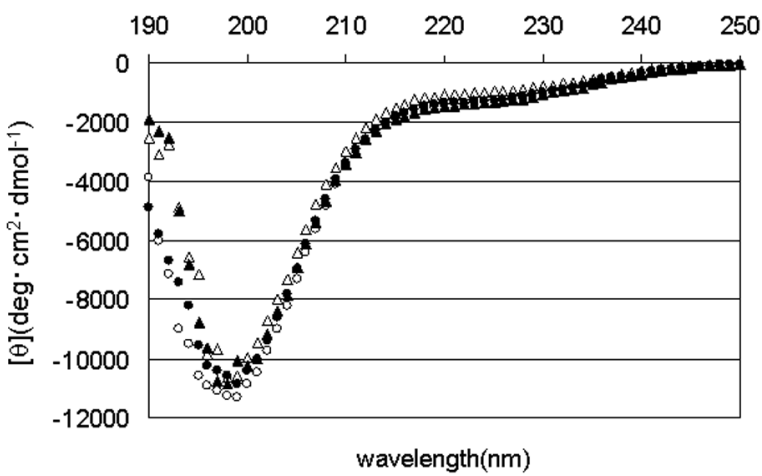

Fig. 2 Effect of applying a voltage of $1 \mathrm{~V}$ on secondary structure of $\alpha$-syn. Far-UV CD spectra for $\alpha$-syn under physiological conditions before incubation $(\bigcirc)$ or after incubation for $18 \mathrm{~h}(\triangle)$ or before the application of voltage (O) or after the application of voltage of $1 \mathrm{~V}$ for $18 \mathrm{~h} \mathrm{( \Delta )}$. The protein concentration of the measured solution was about $23 \mu \mathrm{M}$, at $\mathrm{pH} 7.4$ and $25^{\circ} \mathrm{C}$.

this experiment using only two electrodes. Therefore, the aggregation of $\alpha$-syn might be accelerated by electromobility and condensation near electrode in electric field.

3. 2 Effect of applying $1 \mathrm{~V}$ on the structure of $\alpha$-syn

We also checked, using circular dichroism (CD) measurements, whether $\alpha$-syn aggregate with or without folding. Commonly, the spectrum of $\alpha$-syn was typical of the unfolded structure, with a minimum peak at approximately $198 \mathrm{~nm}$ since a-syn is a natively unfolded protein. As time passes, $\alpha$-syn changes from a random coiled structure to a $\beta$-sheet structure during aggregation. ${ }^{17)}$ The CD spectra of the incubated $\alpha$-syn, including soluble oligomer, showed decrease of minimum peak at approximately $198 \mathrm{~nm} .{ }^{22)}$

Before voltage was applied, the spectrum of $\alpha$-syn was typical of the unfolded structure, with a minimum peak at approximately $198 \mathrm{~nm}$. The spectra of $\alpha$-syn with or without applied voltage after $18 \mathrm{~h}$ showed little difference (Fig. 2). Hence, the secondary structure of $\alpha$-syn did not change under the applied voltage of $1 \mathrm{~V}$ although aggregation did occur. The conformational change to partial folded intermediate of $\alpha$-syn was rate-limiting reaction through aggregation and fibrillation. Thus, it is hard for $\alpha$-syn to fold in acceleration of aggregation under the applied voltage of $1 \mathrm{~V}$.

\section{3 Effect of applying $1 \mathrm{~V}$ on fibrillation and morphology of $\alpha$-syn}

We next investigated the fibrillation of $\alpha$-syn by performing a TfT binding assay after the application of voltage. As a result, the intensity of TfT fluorescence in the presence of $\alpha$-syn to which voltage had been applied did not increase (Fig. 3). Thus, the $\alpha$-syn to which voltage had been applied hardly fibrillated for $18 \mathrm{~h}$ although their aggregation was accelerated (Fig. 1).

We also observed the morphology of $\alpha$-syn to which voltage had been applied, and compared it to the $\alpha$-syn incubated for $200 \mathrm{~h}$ without voltage that showed the similar result of light scattering assay as the control. AFM 


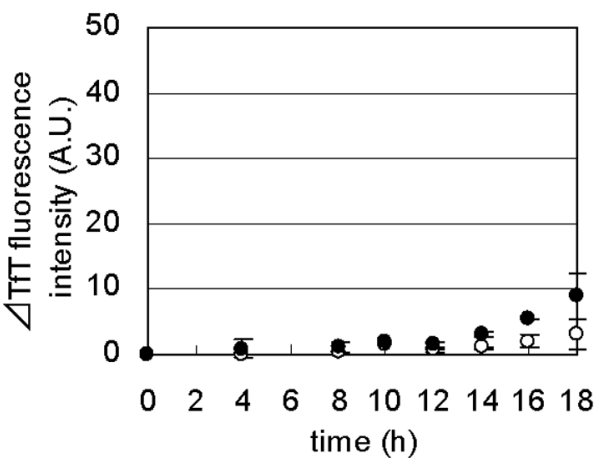

Fig. 3 Effect of applying a voltage of $1 \mathrm{~V}$ on the fibrillation of $\alpha$-syn as monitored by TfT. The symbols represent the intensities of TfT fluorescence against $\alpha$-syn to which no voltage was applied $(\bigcirc)$ or to which a voltage of $1 \mathrm{~V}$ was applied (O). The protein concentration of the solutions was $70 \mu \mathrm{M}$, at $\mathrm{pH} 7.4$ and $37^{\circ} \mathrm{C}$.
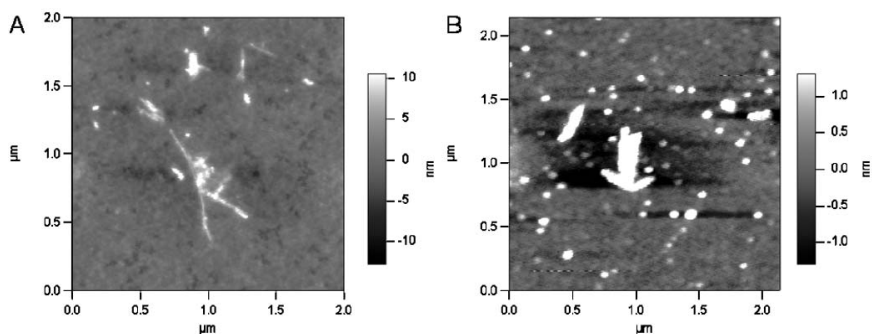

Fig. 4 Atomic force microscopic images of the incubation of $\alpha$-syn to which no voltage was applied for $200 \mathrm{~h}(\mathrm{~A})$ and to which a voltage of $1 \mathrm{~V}$ was applied for $18 \mathrm{~h}$ (B). The protein concentration of the solution was $140 \mu \mathrm{M}$ for (A) or $70 \mu \mathrm{M}$ for (B).

imaging demonstrated that, after the $200 \mathrm{~h}$ incubation, $\alpha$ syn formed amyloid-like fibrils approximately $9 \mathrm{~nm}$ in height and micrometer scale in length (Fig. 4A). However, no mature fibrils were observed among the $\alpha$ syn to which a voltage of $1 \mathrm{~V}$ had been applied for $18 \mathrm{~h}$, and small aggregates with diameters of 3-4 nm were observed (Fig. 4B). The bigger aggregates at the center of the AFM images might be indicative of the assembly of some small aggregates instead of fibrils, since their 3-4 $\mathrm{nm}$ height is the same as that of the smaller aggregate. Therefore, it is reasonable to assume that $\alpha$-syn formed small aggregates instead of fibrils despite the acceleration of its aggregation under the applied voltage of $1 \mathrm{~V}$.

We applied voltage only to increase the frequency of collision of $\alpha$-syn without affecting other factors such as protein-protein interaction. Low $\mathrm{pH}$, high temperature and other factors would affect chemical environmental factors and these effects are not preferable to investigate protein-protein interaction. Thus, this approach might be advantageous in these viewpoints. The application of a voltage of $1 \mathrm{~V}$ did not seem to produce chemically reactive species such as active oxygen and radicals in the protein solution, according to the CV results. In our experiment using only working and counter electrodes, there were no significant change of current and no gas generation near electrode. Thus, under our experimental conditions, the significant changes in $\alpha$-syn aggregation were probably not caused by chemically reactive species and $\mathrm{pH}$ change in electrolysis of water. As our assumption, $\alpha$-syn seemed to gather near the electrode and concentrate in electric field, so aggregation of $\alpha$-syn was accelerated. Aggregation of $\alpha$-syn was accelerated without folding under an applied voltage of $1 \mathrm{~V}$. Additionally, $\alpha$-syn formed small aggregates instead of fibrils despite the acceleration of its aggregation under the applied voltage of $1 \mathrm{~V}$. Therefore, it was indicated that $\alpha$-syn seemed to irregularly interact each other and form small aggregates as a result of rapid aggregation of $\alpha$-syn.

\section{Conclusion}

In this study, we tried to aggregate $\alpha$-syn, which belongs to the group of amyloidogenic proteins, by applying an electric voltage. We evaluated the effect of the applied voltage on the aggregation and fibrillation of $\alpha$ syn, and this is the first attempt to our knowledge. This paper demonstrated that the aggregation of $\alpha$-syn was accelerated when a voltage of $1 \mathrm{~V}$ was applied, without conformational change. The AFM images show that small aggregates were formed as a result of the application of voltage. In addition, they also show that the conformational change of $\alpha$-syn to a partially folded intermediate might be important for the formation of amyloidlike fibrils.

Therefore, this technique might be useful not only to efficiently control aggregation of $\alpha$-syn but also to understand the mechanism of aggregation and fibrillation of $\alpha$ syn.

\section{Acknowledgement}

This work is partly supported by the Grant-in-Aid for the 21st Century COE "Future Nano-Materials" from the Ministry of Education, Culture, Sports, Science and Technology (MEXT) of Japan.

\section{References}

1) C. Gurtner, E. Tu, N. Jamshidi, R. W. Haigis, T. J. Onofrey, C. F. Edman, R. Sosnowski, B. Wallace, and M. J. Heller, Electrophoresis, 23, 1543 (2002).

2) C. F. Edman, D. E. Raymond, D. J. Wu, E. Tu, R. G. Sosnowski, W. F. Butler, M. Nerenberg, and MJ. Heller, Nucleic Acids Res., 25, 4907 (1997).

3) J. M. Kleijn, D. Barten, and M. A. Stuart, Langmuir, 20, 9703 (2004).

4) P. T. Vernier, Y. Sun, L. Marcu, C. M. Craft, and M. A. Gundersen, FEBS Lett., 572, 103 (2004).

5) D. A. Zaharoff and F. Yuan, Bioelectrochemistry, 62, 37 (2004).

6) D. H. Small, S. S. Mok, and J. C. Bornstein, Nat. Rev. Neurosci., 2, 595 (2001).

7) D. W. Dickson, Curr. Opin. Neurol., 14, 423 (2001).

8) M. Baba, S. Nakajo, P. H. Tu, T. Tomita, K. Nakaya, V. M. Lee, J. Q. Trojanowski, and T. Iwatsubo, Am. J. Pathol., 152, 879 (1998).

9) G. Bates, Lancet, 361, 1642 (2003).

10) M. S. Pollanen, D. W. Dickson, and C. Bergeron, J. Neuropathol. Exp. Neurol., 52, 183 (1993).

11) M. G. Spillantini, M. L. Schmidt, V. M. Lee, J. Q. 
Trojanowski, R. Jakes, and M. Goedert, Nature, 388, 839 (1997).

12) L. S. Forno, J. Neuropathol. Exp. Neurol., 55, 259 (1996).

13) V. N. Uversky and A. L. Fink, FEBS Lett., 522, 9 (2002).

14.) R. Jakes, M. G. Spillantini, and M. Goedert, FEBS Lett., 345, 27 (1994).

15) M. Goedert, Nature, 388, 232 (1997).

16) P. H. Weinreb, W. Zhen, A. W. Poon, K. A. Conway, and P. T. Lansbury Jr., Biochemistry, 35, 13709 (1996).

17) V. N. Uversky, J. Li, and A. L. Fink, J. Biol. Chem., 276, 10737 (2001).

18) V. N. Uversky, J. R. Gillespie, and A. L. Fink, Proteins,
41, 415 (2000).

19) S. J. Wood, J. Wypych, S. Steavenson, J. C. Louis, M. Citron, and A. L. Biere, J. Biol. Chem., 274, 19509 (1999).

20) W. Hoyer, T. Antony, D. Cherny, G. Heim, T. M. Jovin, and V. Subramaniam, J. Mol. Biol., 322, 383 (2002).

21) M. Kobayashi, J. Kim, N. Kobayashi, S. Han, C. Nakamura, K. Ikebukuro, and K. Sode, Biochem. Biophys. Res. Commun., 349, 1139 (2006).

22) K. Sode, E. Usuzaka, N. Kobayashi, and S. Ochiai, Biochem. Biophys. Res. Commun., 335, 432 (2005).

23) K. Sode, S. Ochiai, N. Kobayashi, and E. Usuzaka, Int. J. Biol. Sci., 3, 1 (2007). 